\title{
EARNINGS INEQUALITY AND SKILL-BIASED TECHNOLOGICAL CHANGE WITH ENDOGENOUS CHOICE OF EDUCATION
}

\author{
Árpád Ábrahám \\ University of Rochester
}

\begin{abstract}
This article analyzes the impact of stochastic skill-biased technological change on earnings inequality in a general equilibrium OLG model. Wage dispersion is determined by the heterogeneity of skills by allowing for productivity differences due to education, ability, and age. The model performs well in reproducing stylized facts on the time pattern of the U.S. wage distribution and human capital accumulation. In particular, it shows that slow adjustment of the supply of educated labor can itself explain the nonmonotonic time pattern of the college premium. (JEL: D31, J24, J31)
\end{abstract}

\section{Introduction}

The main objective of this article is to present a model that can reproduce some important empirical regularities of the dynamics of wage inequality and human capital accumulation during "skill-biased" technological transition. The model economy has many overlapping generations, and each generation is formed by a continuum of forward-looking heterogenous agents choosing their educational level optimally.

Recently, a vast amount of empirical research has focused on the time pattern of wage differentials and on the changes of the structure of labor supply in the United States for the last four decades. The most important findings of this literature can be summarized by the following list of stylized facts (see, e.g., Katz and Murphy 1992).

1. Return to education (college/high-school wage ratio) moved cyclically. However, during the overall period, the return to college has increased significantly.

Acknowledgments: Discussions with Albert Marcet and Dirk Krueger were very helpful. Comments from seminar and conference participants at UPF, LBS, Bocconi, UAB, Duke, CEF 2002, JEEA 2006, and the 2005 Mannheim Workshop on Heterogenous Agents and Aggregate Uncertainty are acknowledged as well.

E-mail address: Ábrahám: aabraha2@mail.rochester.edu 
2. At the same time, residual wage inequality (wage variation not explained by gender, experience, or education) increased continuously.

3. The relative supply of more educated people and college enrollment increased considerably; however, college enrollment followed a less monotonic pattern.

4. The real wages of high-school graduates decreased in spite of their decreasing relative supply.

One distinctive feature of these facts is that the college wage premium and college enrollment evolved nonmonotonically, whereas the supply of educated labor together with residual wage inequality grew monotonically. The focus of this article is to provide a simple and plausible mechanism that explains the joint behavior of these variables.

It is widely accepted that, in recent decades, developed economies experienced "skill-biased" technological change (i.e., change that favored individuals with better skills); hence we assume that the driving force behind the dynamics of the wage distribution is skill-biased technological change. The key mechanism in this paper is the slow or imperfect adjustment of the supply of college-educated labor to (stochastic) skilled-biased technological change. We identify two straightforward sources of limitations to supply adjustment. First, only young people can still choose their educational attainment, yet they constitute only a small fraction of the total labor force. Second, the cost of acquiring higher education is negatively correlated with ability, implying that only a fraction of a given cohort will find it optimal to attend college.

This implies that (i) it can take several cohorts for the labor supply to adjust to a relatively big demand shift toward educated labor and (ii) because of the overlapping generations structure, expected lifetime earnings differentials depend not only on technological progress but also on the age distribution of the current and future stock of skilled labor. We show that these two reasons imply that increases in wage differentials are typically followed by reductions. Our simulation results demonstrate that this mechanism leads to nonmonotonic (cyclical) behavior of the college premium and college enrollment and to a monotonic increase of the supply of educated labor even under smooth (skill-biased) technological change. At the same time we see that (measured) residual inequality also increases, mostly owing to secular changes in wages and to composition effects. On the other hand, in our simulations the earnings of the unskilled grow as well; although their average ability becomes lower, they also become more scarce and the latter effect dominates.

Both the research objective and the basic structure of the model is closely related to the work of Heckman, Lochner, and Taber (1998). Our model is simpler in some ways, but these simplifications enable us to solve more rigorously for 
the stationary distribution and the transition. ${ }^{1}$ There is a considerable literature on the effect of technological change on earnings inequality and human capital formation (see, e.g., Acemoglu 1998; Caselli 1999; Galor and Moav 2000; Krusell et al. 2000). However, none of these papers can study the relevant medium-run behavior of the college premium and residual inequality simultaneously, because either they assume no heterogeneity with respect to ability or they have only two overlapping generations.

\section{The Model}

Environment. There is a continuum of agents, each living for $n$ periods. In each period, cohort size is constant and normalized to 1, implying that the total population is always $n$. In the first period of her life cycle, each agent decides between accumulating human capital ("going to university") or starting to work as an unskilled worker. If an agent goes to university then, from the next period on, she is a skilled worker; otherwise she remains unskilled for her whole life. Agents are heterogenous in their ability $\gamma$, which has a time-invariant cumulative distribution function $F(\gamma)$. Ability increases productivity and decreases monetary tuition costs $a(\gamma)$ (i.e., $a^{\prime}(\gamma)<0$ ).

We assume linear preferences with homogeneous time discounting where $\delta$ is the discount factor and $c_{i}$ measures the agent's consumption in the $i$ th period of her life. This formulation allows us to plug labor income directly into the utility function, implying that agents maximize their total lifetime expected discounted income. $^{2}$

We define $w_{t}^{0}(\gamma, i)$ and $w_{t}^{1}(\gamma, i)$, respectively, as the unskilled and skilled wage rate of an agent with ability $\gamma$ and age $i$ at time $t$. A newborn agent with ability $\gamma$ at time $t$ will go to college if the following condition is satisfied:

$$
E_{t}\left[\sum_{i=0}^{n-1} \delta^{i} w_{t+i}^{0}(\gamma, i)\right] \leq E_{t}\left[\sum_{i=1}^{n-1} \delta^{i} w_{t+i}^{1}(\gamma, i)\right]-a(\gamma) .
$$

We assume that there is a representative (competitive) firm each period that uses skilled and unskilled labor as production factors. The production function

1. They assume that the agents have perfect foresight of the endogenous variables. Nevertheless, agents do not expect technology to change, although technological change is modelled as a deterministic time trend.

2. Note that the assumption of risk neutrality is not crucial, since risk-averse agents would also maximize their total lifetime expected income if they could borrow and save on a risk-free bond market and face a constant interest rate (given by $1 / \delta-1$ ) and a nonbinding borrowing constraint (to avoid Ponzi schemes). 
is CES (constant elasticity of substitution) with skill-enhancing technological process $A_{t}$ :

$$
Y_{t}=\left(\alpha L_{t}^{\rho}+(1-\alpha)\left(A_{t} H_{t}\right)^{\rho}\right)^{1 / \rho} .
$$

Here, $L_{t}$ and $H_{t}$ denote the employment of unskilled and skilled (educated) workers, respectively. $A_{t}$ is assumed to be lognormal with (nonstochastic) mean equal to $\bar{A}$, and it is assumed to follow a stationary autoregressive process: ${ }^{3}$

$$
\log \left(A_{t+1}\right)=(1-\psi) \log (\bar{A})+\psi \log \left(A_{t}\right)+\varepsilon_{t+1}, \quad \varepsilon_{t} \sim N\left(0, \sigma_{\varepsilon}^{2}\right) .
$$

We model technological progress as a stochastic transition from $A_{0} \ll \bar{A}$ to $\bar{A}$.

We have included only skilled and unskilled labor in the production function without specific correspondence to education, ability, or age. This is allowed because we assume that, although individual productivity endowments of agents depend on ability, age, and education, the productivity units of different agents are prefect substitutes within a given education group. We chose this particular form of skill aggregation because the empirical evidence by Hamermesh (1993) shows that individuals of different ages but with the same schooling level are highly substitutable with each other.

The assumption of perfect substitutability allows us to use the following "linear aggregation schemes," where $p^{0}(\gamma, i)$ and $p^{1}(\gamma, i)$ denote the efficiency unit endowments of an unskilled or skilled agent (respectively) with ability $\gamma$ and age $i$ :

$$
L_{t}=\sum_{i=0}^{n-1} \int_{\gamma \mid s_{t-i}(\gamma)=0} p^{0}(\gamma, i) d F(\gamma) \quad \text { and } \quad H_{t}=\sum_{i=1}^{n} \int_{\gamma \mid s_{t-i}(\gamma)=1} p^{1}(\gamma, i) d F(\gamma) .
$$

The productivity endowments capture changing productivity along the life cycle; that is, $\left\{p^{0}(\gamma, i)\right\}_{i=0}^{n-1}$ represents the age-productivity profile of the unskilled agent with ability $\gamma$. The limits of the integrations are determined by individual optimization in equilibrium, where $s_{t-i}(\gamma) \in\{0,1\}$ indicates whether an individual born at time $t-i$ with ability $\gamma$ attended college or not.

The competitive equilibrium. In order to construct the competitive equilibrium for our model, we define threshold levels for enrolling at university $\left\{\hat{\gamma}_{t}\right\}_{t=0}^{\infty}$, where $\hat{\gamma}_{t}$ refers to the ability level above which all agents decide to become skilled. We also define $U_{t}$ as the proportion of agents enrolled in college at period $t$ (i.e., $\left.U_{t}=\int_{\gamma \mid s_{t}(\gamma)=1} d F(\gamma) d \gamma\right)$.

3. Uncertainty does not play a crucial role in the current form of the model, because agents are risk-neutral. Therefore, our results would be essentially identical under deterministic technological progress. 
DEFINITION 1. The competitive equilibrium is given by stochastic processes of university enrollment thresholds $\left\{\hat{\gamma}_{t}\right\}_{t=0}^{\infty}$, measures of efficiency units of skilled and unskilled workers and university enrollment rates $\left(\left\{H_{t}\right\}_{t=0}^{\infty},\left\{L_{t}\right\}_{t=0}^{\infty}\right.$, and $\left.\left\{U_{t}\right\}_{t=0}^{\infty}\right)$, and wages for skilled and unskilled workers $\left(\left\{w_{t}^{1}(\gamma, i)\right\}_{t=0}^{\infty}\right.$ and $\left.\left\{w_{t}^{0}(\gamma, i)\right\}_{t=0}^{\infty}\right)$, where $U_{-i}(i=1, \ldots, n-1)$ are given and such that the following conditions are satisfied.

1. Skill prices are compatible with profit-maximizing behavior of competitive firms:

$$
\begin{aligned}
& \bar{w}_{t}^{1}=\left(\alpha L_{t}^{\rho}+(1-\alpha)\left(A_{t} H_{t}\right)^{\rho}\right)^{1 / \rho-1}(1-\alpha) A_{t}^{\rho} H_{t}^{\rho-1} \quad \forall t \geq 0 ; \\
& \bar{w}_{t}^{0}=\left(\alpha L_{t}^{\rho}+(1-\alpha)\left(A_{t} H_{t}\right)^{\rho}\right)^{1 / \rho-1} \alpha L_{t}^{\rho-1} \quad \forall t \geq 0 .
\end{aligned}
$$

For individual wages, the linear aggregation scheme implies that

$$
\left.w_{t}^{s}(\gamma, i)=\bar{w}_{t}^{s} p^{s}(\gamma, i) \quad \forall t \geq 0, i=0, \ldots, n-1, s=0,1\right) .
$$

2. The threshold levels and enrollment rates must be consistent with the agents' optimal decisions concerning human capital accumulation. That is, $\hat{\gamma}_{t}$ is given by $^{4}$

$$
a\left(\hat{\gamma}_{t}\right)+w_{t}^{0}\left(\hat{\gamma}_{t}, 0\right)=E_{t}\left[\sum_{i=1}^{n-1} \delta^{i}\left(w_{t+i}^{1}\left(\hat{\gamma}_{t}, i\right)-w_{t+i}^{0}\left(\hat{\gamma}_{t}, i\right)\right)\right]=0 \quad \forall t \geq 0,
$$

with $U_{t}=1-F\left(\hat{\gamma}_{t}\right)$.

3. The stocks of unskilled and skilled labor are compatible with individual decisions. In other words, they must satisfy equation (4) with $\left\{U_{-i}\right\}_{i=1}^{n-1}$ given.

For the subsequent analysis, we assume a normal distribution of ability: $\gamma \sim$ $N\left(\bar{\gamma}, \sigma_{\gamma}^{2}\right)$. We also assume that the age-productivity profiles are separable in ability and age:

$$
p^{s}(\gamma, i)=\gamma+P^{s}(i) \quad(i=0, \ldots, n-1, s=0,1) .
$$

Under these assumptions, we can define a simple law of motion for the stock of skilled labor:

$$
\begin{aligned}
H_{t+1}= & H_{t}+U_{t}\left(\bar{\gamma}_{t}^{1}+P^{1}(0)\right)-U_{t-n+1}\left(\bar{\gamma}_{t-n+1}^{1}+P^{1}(n-1)\right) \\
& +\sum_{i=1}^{n-2}\left[U_{t-i}\left(P^{1}(i+1)-P^{1}(i)\right)\right],
\end{aligned}
$$

4. Ábrahám (2004) discusses the conditions under which we can guarantee the existence and uniqueness of these thresholds. 
where $\bar{\gamma}_{t}^{1}$ and $\bar{\gamma}_{t}^{0}$ denote the average abilities of the skilled and unskilled (respectively) labor force of the generation born at time $t$. It is clear from equation (9) that predicting the evolution of skilled and unskilled labor supply (and hence of wages) after time $t$ requires that we keep track of the educational attainments of all generations living at time $t$.

\section{Quantitative Analysis}

Calibration. We calibrated the model to the U.S. economy. Our general strategy was to use estimates for those parameters that can be observed or at least estimated from actual data. We calibrated the rest of the parameters by matching university enrollment and wage differentials in the nonstochastic steady state to the data. Our final assumption regarding functional forms was that $a(\gamma)=C-\kappa \gamma$. Table 1 displays the parameter values used.

We assumed that individuals live for nine periods: the length of one university career is about five years, and an average person spends 45 years working and/or studying after high school, implying that the natural choice for the discount factor $\delta$ was $0.96^{5}$. Note that $1 /(1-\rho)$ measures the elasticity of substitution between skilled and unskilled labor. This elasticity is typically estimated to be about 1.4 (see, e.g., Katz and Murphy 1992). The age-productivity profiles, $\left\{P^{0}(i)\right\}_{i=0}^{n-1}$ and $\left\{P^{1}(i)\right\}_{i=1}^{n-1}$, were calibrated to the age-earning profiles estimated by Welch (1979).

The moments of the ability distribution $\left(\gamma\right.$ and $\left.\sigma_{\gamma}\right)$ together with the parameters of the educational $\operatorname{cost}(C$ and $\kappa)$ were chosen such that in the nonstochastic steady state of the model would have college enrollment near $27 \%$, which is close to the percentage of college graduates among the young generation in the 1990s. The parameters of technological progress $\left(A_{0}, \bar{A}, \sigma_{\varepsilon}, \psi\right)$ were chosen such that, on average, the observed increase in enrollment is obtained along the transition path and the transition takes place in 15 periods.

Simulation results. Figure 1 summarizes the results of our simulations. We study the average transition path toward the stationary distribution of $A_{t}$. In general, the results are satisfactory and reproduce reasonably well the joint behavior of labor supply, college wage premium, residual inequality, and (to a lesser extent) university enrollment assuming only smooth skilled-biased technological change.

TABLE 1. Parameters for calibration.

\begin{tabular}{cccccccccccc}
\hline$n$ & $\alpha$ & $\rho$ & $\delta$ & $\bar{\gamma}$ & $\sigma_{\gamma}$ & $\kappa$ & $C$ & $\sigma_{\varepsilon}$ & $\psi$ & $\bar{A}$ & $A_{0}$ \\
\hline 9 & 0.55 & 0.29 & $0.96^{5}$ & 0.2 & 0.1 & 1 & 0.6 & 0.05 & $0.95^{5}$ & 1.5 & 0.5 \\
\hline
\end{tabular}



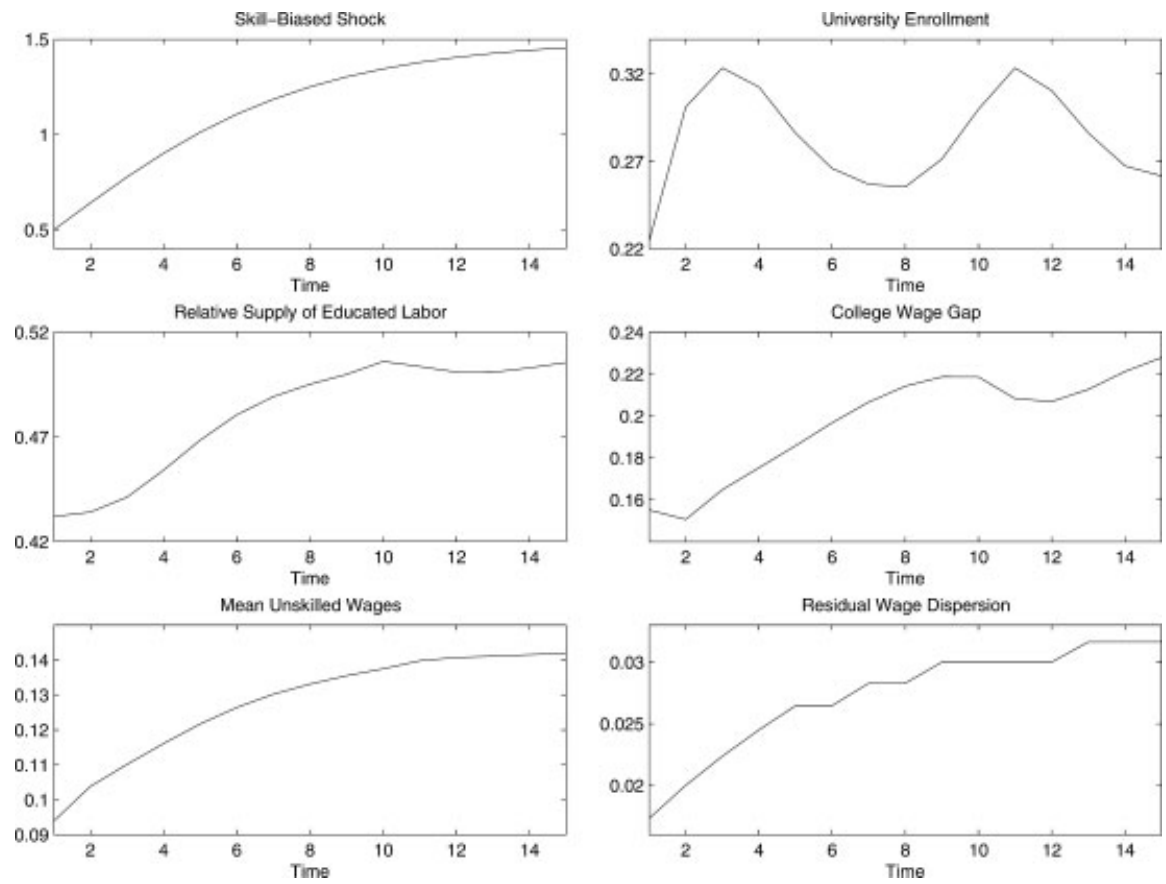

FIGURE 1. Wage inequality and human capital accumulation during skill-biased technological transition.

However, enrollment proved to be too volatile, and unskilled real wages do not show a decreasing pattern.

Observe first that, even with smooth technological change, the behavior of enrollment and wage differentials has a nonmonotonic time evolution in the last 10 periods of the transition, as in the data. The early generations invest extensively in human capital both because they expect increasing wage differentials during their life cycle and because the pre-existing generations have low levels of education. The wage gap is still increasing, because they enter with a one-period lag and with low experience and because $A_{t}$ has a direct effect on the wage gap. However, as these early generations gain experience, future generations start to reduce their enrollment because the previous generations push down the return from education. This reduction in enrollment helps maintain an increasing wage differentials because $A_{t}$ is still increasing. However, subsequent generations know that the initial generations with large education stock will retire soon and hence that wage differentials will increase during their life cycle, so they start to accumulate more human capital. This temporary overflow of high-skilled people pushes down their marginal productivity and consequently their wage premium in the short run, leading to a reduction in enrollment. This cyclical behavior of 
enrollment and the wage gap continues until the steady state is reached; it is a consequence of the finite individual time horizon and of the slow adjustment of the educated labor supply. Furthermore, the new generations entering the market are still better educated than the ones retiring, so the relative supply of educated labor is increasing continuously.

At the same time, residual earnings inequality is increasing. We have defined residual inequality $\left(\tilde{\sigma}_{t}\right)$ as the standard deviation of wages after controlling for wage dispersion due to education and age. Defining $\xi\left(\hat{\gamma}_{t-i}\right)$ and $\zeta\left(\hat{\gamma}_{t-i}\right)$ as the standard deviations of a truncated normal variable when the truncation is $\gamma>\hat{\gamma}_{t-i}$ and $\gamma<\hat{\gamma}_{t-i}$, respectively, we can express $\tilde{\sigma}_{t}$ as

$$
\tilde{\sigma}_{t} \equiv \sqrt{\frac{\left(\bar{w}_{t}^{0}\right)^{2} \sum_{i=0}^{n-1}\left(1-U_{t-i}\right) \zeta^{2}\left(\hat{\gamma}_{t-i}\right)+\left(\bar{w}_{t}^{1}\right)^{2} \sum_{i=1}^{n-1} U_{t-i} \xi^{2}\left(\hat{\gamma}_{t-i}\right)}{n-U_{t}}} .
$$

It is obvious from this expression that residual dispersion depends on the levels of marginal productivities, $\bar{w}_{t}^{s}$. We know that technological change alone would improve the productivity of both skilled and unskilled labor, yet equation (10) shows that residual inequality depends on other variables as well. Ceteris paribus, it depends positively on $U_{t}$, because higher enrollment decreases not only the weight of unskilled young people whose productivity $\bar{w}_{t}^{0}$ is lower but also the within-group inequality $\left(\zeta\left(\hat{\gamma}_{t}\right)\right)$ in that group. The impact of the other relevant threshold levels $\left(\left\{\hat{\gamma}_{t-i}\right\}_{i=1}^{n-1}\right)$ is more complicated, but it can be demonstrated that they alone would imply a reduction in $\tilde{\sigma}_{t}$ during the transition. It is clear from the last panel of Figure 1 that the first two effects dominate. This result is compatible with the results of Lemieux (2006), who shows empirically that most of the growth in measured residual inequality is due to secular changes in wages and composition effects similar to the ones discussed here.

We have less appealing results for average unskilled wages, given by

$$
\left[\left(\alpha L_{t}^{\rho}+(1-\alpha)\left(A_{t} H_{t}\right)^{\rho}\right)^{1 / \rho-1} \alpha L_{t}^{\rho-1}\right] \frac{\sum_{i=0}^{n-1}\left(1-U_{t-i}\right)\left(\bar{\gamma}_{t-i}^{0}+P^{0}(i)\right)}{\sum_{i=0}^{n-1}\left(1-U_{t-i}\right)} .
$$

Here again, several forces are working in opposite directions. Technological change implies increase in enrollment (at least in the long run), which in turn implies deterioration of the average ability level of the unskilled $\left(\bar{\gamma}_{t-i}^{0}\right)$; this impact itself would imply a reduction in average unskilled wages. However, technological change has a direct impact also on the marginal productivity of unskilled labor. First, because the two inputs are complementary, an increase in $A_{t}$ will increase $\bar{w}_{t}^{0}$. Second, decreasing $L_{t}$ implies that the marginal productivity of unskilled 
labor increases because it becomes more scarce. It is clear from our figure that the two direct forces dominate the reduction in average ability.

The introduction of (mostly unskilled) immigration and varying cohort size to the model might help maintain lower marginal productivity of unskilled labor and could thus address the issue of increasing unskilled wages. Finally, we have abstracted from changes in educational policies during this period that made college education more affordable; this factor could at least partially explain why our simulations generate larger drops in enrollment relative to the data.

\section{Conclusions}

In this article we presented a stochastic model of wage differentials and human capital accumulation in the presence of skill-biased technological progress. The model reproduces reasonably well the key stylized facts regarding the joint dynamic behavior of wage premium, relative supply of skilled labor, and residual inequality. In particular, we have shown that investment in human capital may fluctuate even under smooth technological change as a result of the finite horizon of individual decisions and the limited adjustment of the skilled labor supply. These oscillations can cause long-lasting cycles in the college wage gap.

The model is well designed to study efficiency and distributional effects of different policies (e.g., tuition subsidies, income taxes) influencing educational choice. Ábrahám (2004) performs such analysis. Finally, in most countries, skillbiased technological change has also decreased the participation of low-skilled individuals in the labor force. The model can easily be extended to home production or to minimum wage requirements and unemployment benefits and so enable us to address the interaction of skill-biased technological progress, labor force participation, social/unemployment assistance, and education policies.

\section{References}

Ábrahám, Árpád (2004). "Educational Policy and Wage Inequality with Skill-biased Technological Change." Working paper, University of Rochester.

Acemoglu, Daron (1998). "Why Do New Technologies Complement Skills? Directed Technological Change and Wage Inequality." Quarterly Journal of Economics, 113(4), 1055-1089.

Caselli, Francesco (1999). "Technological Revolutions.” American Economic Review, 89(1), 78-102.

Galor, Oded, and Omar Moav (2000). "Ability-biased Technological Transition, Wage Inequality, and Economic Growth.” Quarterly Journal of Economics, 115(2), 469-498.

Hamermesh, Daniel (1993). Labor Demand. Princeton University Press.

Heckman, James, Lance Lochner, and Christopher Taber (1998). "Explaining Rising Wage Inequality: Explorations with a Dynamic General Equilibrium Model of Labor Earnings with Heterogeneous Agents." Review of Economic Dynamics, 1(1), 1-58.

Katz, Lawrence, and Kevin M. Murphy (1992), "Changes in Relative Wages, 1963-1987: Supply and Demand Factors." Quarterly Journal of Economics, 107(1), 31-78. 
Krusell Per, Lee Ohanian, Jose-Victor Rios-Rull, and Gianluca Violante (2000). "Capitalskill Complementarity and Inequality: A Macroeconomic Analysis." Econometrica, 68, $1029-1054$.

Lemieux, Thomas (2006). "Increasing Residual Wage Inequality: Composition Effects, Noisy Data, or Rising Demand for Skill?” American Economic Review, 96(3), 461-498.

Welch, Finis (1979). "Effects of Cohort Size on Earnings: The Baby Boom Babies' Financial Bust." Journal of Political Economy, 87(5/2), S65-S97. 